\title{
Investigation of Cyclists' Attitudes and Perceptions Towards other Road Users: Evidence from a Case Study in Thessaloniki, Greece
}

\author{
Evangelos Paschalidis ${ }^{1}$, Michail Prodromou ${ }^{2}$, Socrates Basbas ${ }^{3}$ \\ and Ioannis Politis ${ }^{4}$ \\ ${ }^{1}$ Choice Modelling Centre, Institute for Transport Studies, University of Leeds, \\ United Kingdom \\ ${ }^{2,4}$ Department of Civil Engineering, Aristotle University of Thessaloniki, Faculty \\ of Engineering, Thessaloniki, Greece \\ ${ }^{3}$ Department of Rural and Surveying Engineering, Aristotle University of \\ Thessaloniki, Faculty of Engineering, Thessaloniki, Greece \\ ${ }^{1}$ tsep@leeds.ac.uk, ${ }^{2}$ mineth21@gmail.com, ${ }^{3}$ smpasmpa@auth.gr, \\ ${ }^{4}$ pol@civil.auth.gr
}

\begin{abstract}
The main objective of this paper is the investigation of interaction between the cyclists and the pedestrians as well as with the road traffic. Within the framework of the study, a revealed preference survey was conducted in order to record the preferences of the cyclists as regard to the coexistence with pedestrians and vehicular traffic. In general, the cyclists expressed their preference to use separate infrastructure from pedestrians and vehicles. However, the current interaction does not seem to be a barrier for cycling. Additionally, the perceived responsibility for a conflict between the cyclists, the pedestrians and the vehicular traffic was investigated. It was found that cyclists tend to give more responsibility to the car drivers and they do not blame themselves for a conflict or/and an accident with a car. On the other hand, they tend to be more lenient for incidents occurred with pedestrians.
\end{abstract}

Keywords: bicycle, pedestrian, vehicular traffic, conflict, perceived responsibility, bicycle infrastructure, shared spaces

\section{Introduction}

Bicycle represents one of the most important transport means for the promotion of sustainable mobility. The shift from motorized means of transportation to bicycle is able to provide benefits to public health and also reduce population's mortality [1]. The benefits from bicycle use to health, environment and also to the operation of transportation system is also highlighted by other studies too [2, 3]. In the aforementioned studies is reported that the increase of bicycle use results in the reduction of gas emissions, noise and congestion; therefore, the overall fatalities decrease.

The use of bicycle can be considered therefore as a significant alternative of mode choice especially for urban trips and policy makers should shift their planning towards the increase of bicycle use. However, very little is known about the perception of cyclists when they have to interact with the rest users of the road, their expectations and preferences. A better knowledge of these issues could contribute in an increased use of bicycle which will also have a greater impact, in terms of personal and public health and sustainability. The main purpose of the present study is to investigate the perception of cyclists about pedestrians and cars, in the case of a conflict with them. 
For this purpose, a revealed preference questionnaire survey was conducted and the main findings are given in the next sections of the paper.

\section{Literature Review}

The coexistence of pedestrians, cyclists and motor vehicles inevitably results in a number of interactions among them. These interactions may also cause a sense of stress, inconvenience or/and uncertainty to the involved parts. Owens [4] formulated some definitions in order to describe the term of "conflict" between pedestrians and cyclists, at shared recreational paths. More specifically, he described conflict as a perpetual competitiveness between users, during an effort to achieve their desired and perceived satisfaction from the infrastructure use. Obviously, conflict occurs when a group of users perceives that another group "jeopardizes" their expectations (e.g., comfort and safety). Therefore, conflict is a phenomenon that derives from a number of subjective goals and expectations, which every user sets. The term of "crowding" was introduced by the same author as a factor which is able to result in conflict. From all the above it may be concluded that conflict is possible to occur not necessarily because of the physical contact among users [5].

Regarding the interaction between cyclists and pedestrians, studies are mostly focused on the latter. In particular, pedestrians were found to be annoyed by their coexistence with cyclists [6]. More specifically, in this study, they evaluated lower the level of service of sidewalks which were also used by cyclists. The factors which influence pedestrians' perception of danger are primarily the path's width, which is also related to the lateral distance during passing and meeting events, the physical ability and age of pedestrians and finally the speed of cyclists [7]. Especially the speed of cyclists influences negatively the perception of pedestrians regardless its magnitude. Moreover, according to a study conducted by Uzell et al., [8], cyclists tend to reduce their speed when they approach pedestrians and are also more positive for sharing paths, compared to the latter. Additionally, in the same study, users stated to a less extent that perceived a conflict while a minority of them reported a collision. The same outcome, regarding cyclists' speed reduction was also found in a study conducted by Singh [9]. Concerning users' perception, cyclists evaluate the quality of segregated shared paths as better, compared to the mixed paths [10]. However, both cyclists and pedestrians stated that in mixed paths users show more consideration for the others; while on segregated paths incidents of non-compliance are more possible to occur. Also, the proportion of pedestrians' non-compliant behaviour was almost double than cyclists'. Moreover, with reference to Ružić [11], cyclists on shared paths perceived approximately double rate of conflict, compared to pedestrians. Additionally, they regarded themselves as more concerned to the unpredictable maneuvers of the others. Also, the majority of respondents expressed willingness for the application of segregation.

As far as it concerns their interaction with vehicular traffic, cyclists feel safer when they travel separated from it [12]. With reference to a study conducted by Chataway et al., [13], cyclists prefer separated bicycle lanes since they feel inconvenient by the presence of motorized traffic. This annoyance was found related to the gender and the frequency of car and bicycle use. The frequency, of car and bicycle use, discourages cyclists from cycling [14]. Gender and years of experience were also identified as discouraging factors by O'Connor and Brown [15]. In this same study, the majority of cyclists reported that car drivers feel annoyed by the presence of bicycles and are hostile.

Concerning their behaviour, drivers tend to reduce their speed when they interact with bicycles [16]. Additionally, it is observed that drivers do not behave aggressively to cyclists; however, their presence causes stress and negative attitude to them [17]. 
The unpredictable behaviour of cyclists as well their peculiarity as road users (they ride without license and insurance) may cause the aforementioned drivers' attitude. However, according to the same study, drivers recognize that they should drive more carefully when they move near them. Finally, in a study of Johnson et al., [18] is reported that drivers who also cycle perceive cyclists' riding behaviour as safe while the rest drivers reported that cyclists are characterized by unpredictable behaviour.

\section{Undertaken Research and Questionnaire Structure}

As mentioned already, the purpose of the present paper is the investigation of cyclists' profile together with their perception during their interaction with pedestrians and motor vehicles. Within the context of this examination, a revealed preference questionnaire survey was conducted under the form of personal interviews which addressed to cyclists exclusively. The survey took place between 2/7/2013 and $19 / 7 / 2013$ at the city of Thessaloniki in Greece and more specifically at the shared recreational path along the coastal zone of the city. The study area is a segregated shared path. It is primarily used by pedestrians and cyclists, but the latter are separated from pedestrians with a bicycle lane. The segregation is accomplished with painted lines. This specific area was selected because of its high use by cyclists, especially during the period of summer. The infrastructure is accessed by cyclists coming from all the areas all the city, therefore it was considered that the sample would be composed by respondents that highly interact with vehicular traffic. Also, all the respondents were assumed to interact with pedestrians due to the nature of the infrastructure. The simple random sampling method was used for the survey conduction. Finally, 306 questionnaires were collected and used as valid for further analysis $[19,20]$.

All the questions of the conducted survey were formed as revealed preference. The purpose for this approach was the better identification of the cyclists' mobility characteristics and habits as well as the capture of their attitudes and perceptions about the other road users. The questionnaire itself consisted of 5 sections and 20 questions. More particularly, the first section refers to the social characteristics of the participants (gender, age). The second section includes questions relevant to the mobility characteristics of cyclists and focuses on their preferences regarding bicycle use. These include frequency and duration of cycling, cycling purpose(s), factors that discourage users from cycling etc. Additionally, other factors revealed in this section of the questionnaire was the car ownership, the use of public transport, the motorcycle ownership, the possibility to conflict with a car and pedestrian, the trip length and the perceived level of the cycling infrastructure in the city. For the perception questions, a 5 point Likert scale was used, where 1 represents "not at all" and 5 represents "very much"). The third section focuses on a cyclists" conflict past experience with pedestrian. In this part the answer was open-type and the respondents were able to describe their last conflict event with a pedestrian. The events then were coded in cases, as shown in Table 1. Moreover, the cyclists had to assign the responsibility for the reported event, as they perceived it. Initially, perceived responsibility was attached in terms of percentages (0-100\%) and were recoded into: 1 . Exclusively the cyclist, 2 . The cyclist more, 3 . Both users equally, 4. The pedestrian more, 5 . Exclusively the pedestrian. Finally, regardless the reported event, participants were asked to give their opinion about the issue of priority, as perceived by them, when cyclists are met with pedestrians. Similarly, to the third section, the fourth section focuses on a cyclists' conflict past experience with motor vehicle, by investigating the same issues as in the previous case. The fifth and final section examines cyclists' preferences regarding the type of paths, their behavior when they coexist with pedestrians and motorized traffic etc. 


\section{Descriptive and Inferential Statistics}

The data analysis is based on descriptive and inferential statistics. The descriptive statistics represent an initial part of the analysis where the used variables along with some primary findings, regarding the collected data, are presented. The inferential statistics provide the possibility of a more complex examination of the data through bivariate correlations.

\subsection{Descriptive Statistics}

Table 1 presents the most significant of the variables developed and examined in the analysis, together with a short description. The variables are based on the questions of the undertaken survey.

Table 1. Descriptive Statistics of the Variables

\begin{tabular}{|c|c|c|c|c|}
\hline Variable name & Descriprion & Responds & Frequency & $\%$ \\
\hline \multirow[t]{2}{*}{ gender } & \multirow[t]{2}{*}{ Gender of respondent } & Male & 60 & 19.6 \\
\hline & & Female & 246 & 80.4 \\
\hline \multirow[t]{5}{*}{ age } & \multirow[t]{5}{*}{ Age of respondent } & $19-24$ & 66 & 21.6 \\
\hline & & $25-39$ & 174 & 56.9 \\
\hline & & $40-54$ & 43 & 14.1 \\
\hline & & $55-64$ & 18 & 5.9 \\
\hline & & $>65$ & 5 & 1.6 \\
\hline \multirow[t]{4}{*}{ purpose } & \multirow{4}{*}{$\begin{array}{l}\text { Trip purpose (during } \\
\text { interview) }\end{array}$} & Exercise/ Health & 40 & 13.1 \\
\hline & & Recreation & 211 & 69.0 \\
\hline & & Other & 8 & 1.3 \\
\hline & & Personal reasons & 47 & 15.4 \\
\hline \multirow[t]{6}{*}{ frequency } & \multirow[t]{6}{*}{ Frequency of cycling } & Every day & 130 & 42.5 \\
\hline & & 4-5 days/ week & 18 & 5.9 \\
\hline & & 3 days/ week & 93 & 30.4 \\
\hline & & 1-2 days/ week & 46 & 15.0 \\
\hline & & 1-2 days/ month & 9 & 2.9 \\
\hline & & Seldom & 10 & 3.3 \\
\hline \multirow[t]{3}{*}{ duration } & \multirow[t]{3}{*}{ Duration per trip } & $11-20 \mathrm{~min}$ & 12 & 3.9 \\
\hline & & $21-60 \mathrm{~min}$ & 51 & 16.7 \\
\hline & & $>1$ hour & 243 & 79.4 \\
\hline \multirow[t]{2}{*}{ exercise } & \multirow[t]{2}{*}{ Bicycle use for exercise } & No & 55 & 18.0 \\
\hline & & Yes & 251 & 82.0 \\
\hline \multirow[t]{2}{*}{ reach_dest } & \multirow{2}{*}{$\begin{array}{l}\text { Bicycle use for commuting } \\
\text { (go to work/ school) }\end{array}$} & No & 192 & 62.7 \\
\hline & & Yes & 114 & 37.3 \\
\hline \multirow[t]{2}{*}{ recreation } & \multirow[t]{2}{*}{ Bicycle use for recreation } & No & 55 & 18.0 \\
\hline & & Yes & 251 & 82.0 \\
\hline \multirow[t]{2}{*}{ car_avail } & \multirow{2}{*}{$\begin{array}{l}\text { Car availability within the } \\
\text { household }\end{array}$} & No & 20 & 6.5 \\
\hline & & Yes & 286 & 93.5 \\
\hline \multirow[t]{2}{*}{ motorcycle_avail } & \multirow[t]{2}{*}{ Motorcycle ownership } & No & 221 & 72.2 \\
\hline & & Yes & 85 & 27.8 \\
\hline \multirow[t]{5}{*}{ car_occup_avert } & \multirow{5}{*}{$\begin{array}{l}\text { Evaluation of car occupancy } \\
\text { as a factor that will } \\
\text { discourage the respondent } \\
\text { from cycling ( } 1=\text { not at all, } 5 \\
=\text { very much) }\end{array}$} & 1 & 188 & 61.4 \\
\hline & & 2 & 44 & 14.4 \\
\hline & & 3 & 41 & 13.4 \\
\hline & & 4 & 17 & 5.6 \\
\hline & & 5 & 16 & 5.2 \\
\hline \multirow[t]{5}{*}{ public_transp_avert } & \multirow{5}{*}{$\begin{array}{l}\text { Evaluation of public } \\
\text { transport use as a factor that } \\
\text { will discourage the } \\
\text { respondent from cycling ( } 1= \\
\text { not at all, } 5 \text { = very much) }\end{array}$} & 1 & 181 & 59.2 \\
\hline & & 2 & 58 & 19.0 \\
\hline & & 3 & 39 & 12.7 \\
\hline & & 4 & 15 & 4.9 \\
\hline & & 5 & 13 & 4.2 \\
\hline motorc_occup_avert & Evaluation of motorcycle & 1 & 25 & 29.4 \\
\hline & occupancy as a factor that & 2 & 19 & 22.4 \\
\hline & will discourage the & 3 & 13 & 15.3 \\
\hline & respondent from cycling $(1=$ & 4 & 12 & 14.1 \\
\hline & not at all, $5=$ very much) & 5 & 16 & 18.8 \\
\hline
\end{tabular}




\begin{tabular}{|c|c|c|c|c|}
\hline \multirow[t]{5}{*}{ car_confl_avert } & \multirow{5}{*}{$\begin{array}{l}\text { Evaluation of a potential } \\
\text { conflict with car as a factor } \\
\text { that will discourage the } \\
\text { respondent from cycling ( } 1= \\
\text { not at all, } 5 \text { = very much) }\end{array}$} & 1 & \begin{tabular}{l|l}
150 \\
\end{tabular} & 49.0 \\
\hline & & 2 & 48 & 15.7 \\
\hline & & 3 & 51 & 16.7 \\
\hline & & 4 & 37 & 12.1 \\
\hline & & 5 & 20 & 6.5 \\
\hline \multirow{5}{*}{ ped_confl_avert } & \multirow{5}{*}{$\begin{array}{l}\text { Evaluation of a potential } \\
\text { conflict with pedestrian as a } \\
\text { factor that will discourage } \\
\text { the respondent from cycling } \\
\text { (1= not at all, } 5 \text { = very } \\
\text { much) }\end{array}$} & 1 & 196 & 64.1 \\
\hline & & 2 & 65 & 21.2 \\
\hline & & 3 & 21 & 6.9 \\
\hline & & 4 & 15 & 4.9 \\
\hline & & 5 & 9 & 2.9 \\
\hline \multirow[t]{5}{*}{ long_dist_avert } & \multirow{5}{*}{$\begin{array}{l}\text { Evaluation of long distances } \\
\text { as a factor that will } \\
\text { discourage the respondent } \\
\text { from cycling ( } 1=\text { not at all, } 5 \\
\text { = very much) }\end{array}$} & 1 & 112 & 36.6 \\
\hline & & 2 & 49 & 16.0 \\
\hline & & 3 & 66 & 21.6 \\
\hline & & 4 & 46 & 15.0 \\
\hline & & 5 & 33 & 10.8 \\
\hline \multirow[t]{5}{*}{ infr_lack_avert } & \multirow{5}{*}{$\begin{array}{l}\text { Evaluation unavailability of } \\
\text { bicycle infrastructure as a } \\
\text { factor that will discourage } \\
\text { the respondent from cycling } \\
\text { (1= not at all, } 5=\text { very } \\
\text { much) }\end{array}$} & 1 & 74 & 24.2 \\
\hline & & 2 & 32 & 10.5 \\
\hline & & 3 & 72 & 23.5 \\
\hline & & 4 & 73 & 23.9 \\
\hline & & 5 & 55 & 18.0 \\
\hline \multirow[t]{2}{*}{ ped_confl } & \multirow{2}{*}{$\begin{array}{l}\text { Respondent has experienced } \\
\text { a conflict with a pedestrian }\end{array}$} & No & 109 & 35.6 \\
\hline & & Yes & 197 & 64.4 \\
\hline \multirow[t]{6}{*}{ ped_confl_type } & \multirow[t]{6}{*}{$\begin{array}{l}\text { Type of conflict with } \\
\text { pedestrian }\end{array}$} & $\begin{array}{l}\text { Conflict at the shared-use } \\
\text { path of the coastal zone }\end{array}$ & 74 & 37.6 \\
\hline & & $\begin{array}{l}\text { Conflict at the shared-use } \\
\text { path of the coastal } \\
\text { zone(narrow segment) }\end{array}$ & 68 & 34.5 \\
\hline & & Conflict on a sidewalk & 15 & 7.6 \\
\hline & & $\begin{array}{l}\text { Conflict on a sidewalk } \\
\text { (with a bicycle lane) }\end{array}$ & 8 & 4.1 \\
\hline & & $\begin{array}{l}\text { Conflict with a pedestrian } \\
\text { crossing the road (no } \\
\text { crosswalk) }\end{array}$ & 21 & 10.7 \\
\hline & & $\begin{array}{l}\text { Conflict with a pedestrian } \\
\text { crossing the road } \\
\text { (crosswalk) }\end{array}$ & 11 & 5.6 \\
\hline \multirow[t]{5}{*}{ ped_respons } & \multirow{5}{*}{$\begin{array}{l}\text { Perceived responsibility for } \\
\text { the reported conflict with } \\
\text { pedestrian }\end{array}$} & Exclusively the cyclist & 21 & 10.7 \\
\hline & & The cyclist more & 10 & 5.1 \\
\hline & & Both users equally & 22 & 11.2 \\
\hline & & The pedestrian more & 53 & 26.9 \\
\hline & & Exclusively the pedestrian & 91 & 46.2 \\
\hline \multirow[t]{4}{*}{ ped_priority } & \multirow[t]{4}{*}{$\begin{array}{l}\text { Perceived priority when a } \\
\text { cyclist meets a pedestrian }\end{array}$} & $\begin{array}{l}\text { Pedestrians always have } \\
\text { the priority }\end{array}$ & 86 & 43.7 \\
\hline & & $\begin{array}{l}\text { Cyclist always has the } \\
\text { priority }\end{array}$ & 17 & 8.6 \\
\hline & & $\begin{array}{l}\text { Priority depends on the } \\
\text { type of infrastructure } \\
\text { users meet }\end{array}$ & 92 & 46.7 \\
\hline & & Agreement between users & 2 & 1.0 \\
\hline \multirow[t]{2}{*}{ car_confl } & \multirow{2}{*}{$\begin{array}{l}\text { Respondent has experienced } \\
\text { a conflict with a car }\end{array}$} & No & 140 & 45.8 \\
\hline & & Yes & 166 & 54.2 \\
\hline \multirow[t]{5}{*}{ car_confl_type } & \multirow[t]{5}{*}{ Type of conflict with car } & $\begin{array}{l}\text { Aggressive driving } \\
\text { behaviour on a road } \\
\text { segment }\end{array}$ & 62 & 37.3 \\
\hline & & $\begin{array}{l}\text { Illegal car movement on a } \\
\text { road segment }\end{array}$ & 12 & 7.2 \\
\hline & & Conflict at an intersection & 52 & 31.3 \\
\hline & & $\begin{array}{l}\text { Illegal bicycle movement } \\
\text { on a road segment }\end{array}$ & 10 & 6.0 \\
\hline & & $\begin{array}{l}\text { Car is turning at an } \\
\text { intersection and blocks } \\
\text { bicycle's course }\end{array}$ & 17 & 10.2 \\
\hline
\end{tabular}




\begin{tabular}{|c|c|c|c|c|}
\hline & & $\begin{array}{l}\text { Parked car passenger } \\
\text { opens the door when } \\
\text { cyclists passes }\end{array}$ & 13 & 7.8 \\
\hline \multirow[t]{5}{*}{ car_respons } & \multirow{5}{*}{$\begin{array}{l}\text { Perceived responsibility for } \\
\text { the reported conflict with car }\end{array}$} & Exclusively the cyclist & 10 & 6.0 \\
\hline & & The cyclist more & 3 & 1.8 \\
\hline & & Both users equally & 20 & 12.0 \\
\hline & & The driver more & 47 & 28.3 \\
\hline & & Exclusively the driver & 86 & 51.8 \\
\hline \multirow[t]{3}{*}{ car_priority } & \multirow[t]{3}{*}{$\begin{array}{l}\text { Perceived priority when a } \\
\text { cyclist meets a car }\end{array}$} & $\begin{array}{l}\text { Cyclists always have the } \\
\text { priority }\end{array}$ & 66 & 39.8 \\
\hline & & $\begin{array}{l}\text { Cars always have the } \\
\text { priority }\end{array}$ & 10 & 6.0 \\
\hline & & $\begin{array}{l}\text { Bicycle should be taken } \\
\text { into account as any other } \\
\text { vehicle }\end{array}$ & 90 & 54.2 \\
\hline \multirow[t]{2}{*}{ infr_ped } & \multirow{2}{*}{$\begin{array}{l}\text { Respondent's preferred type } \\
\text { of infrastructure when } \\
\text { interacts with pedestrians }\end{array}$} & Mixed & 7 & 2.3 \\
\hline & & Segregated & 299 & 97.7 \\
\hline \multirow[t]{2}{*}{ infr_traffic } & \multirow{2}{*}{$\begin{array}{l}\text { Respondent's preferred type } \\
\text { of infrastructure when } \\
\text { interacts with motorized } \\
\text { traffic }\end{array}$} & $\begin{array}{l}\text { Cycle lane on the } \\
\text { sidewalk }\end{array}$ & 73 & 23.9 \\
\hline & & Cycle lane across the road & 233 & 76.1 \\
\hline
\end{tabular}

The majority of the collected sample consists of men (80\%). The low levels of the female gender regarding the cyclists' sample can be also observed in other similar studies [21, 22]. The descriptive analysis also showed that cyclists are mostly young and middle aged persons while cyclists aged more than 55 years represented less than $8 \%$ of the sample. It is worth highlighting that participants aged between 25-39 years old represented approximately $57 \%$ of respondents. These results indicate that bicycle use is observed to face gender and age differentiations.

Concerning their trip purpose, during the interview, $83 \%$ of the interviewees stated bicycle use for recreational purposes. This outcome derived mostly due to the nature of the study area (recreational shared-use path) and the period when the survey took place (summer). Moreover, 12\% reported bicycle use for exercise. Regarding frequency of riding, almost $43 \%$ stated a daily use of bicycle. Additionally, $30 \%$ reported bicycle use 3 days per week while finally, the percentages of seldom users consisted approximately $6 \%$ of the sample. Besides the high frequency of riding the respondents also reported long durations of bicycle use per trip. More particularly, $79 \%$ stated more than an hour of riding per trip. The high frequency of bicycle usage may be possibly biased because of the survey period; the bicycle usage for this specific infrastructure is highly increased during the summer months, compared to winter, and this may possibly biased the results towards higher values. Therefore, if the survey had been conducted in a different season, different values of bicycle use may had occurred.

Figure 1 illustrates the stated trip purposes of the responders. From the results of this question derived the conclusion that cyclists mostly ride for exercise and recreation. Generally, it was observed that apart from those two choices, the "no" answers (e.g., no I do not cycling for this purpose) were more than the "yes" answers. 
It is worth highlighting that the least positive answers showed at the "commuting (go to work/ school)" trip purpose. Therefore, it can be assumed that cyclists prefer to ride for primarily for recreation purposes and less for other trips such us commuting trips.

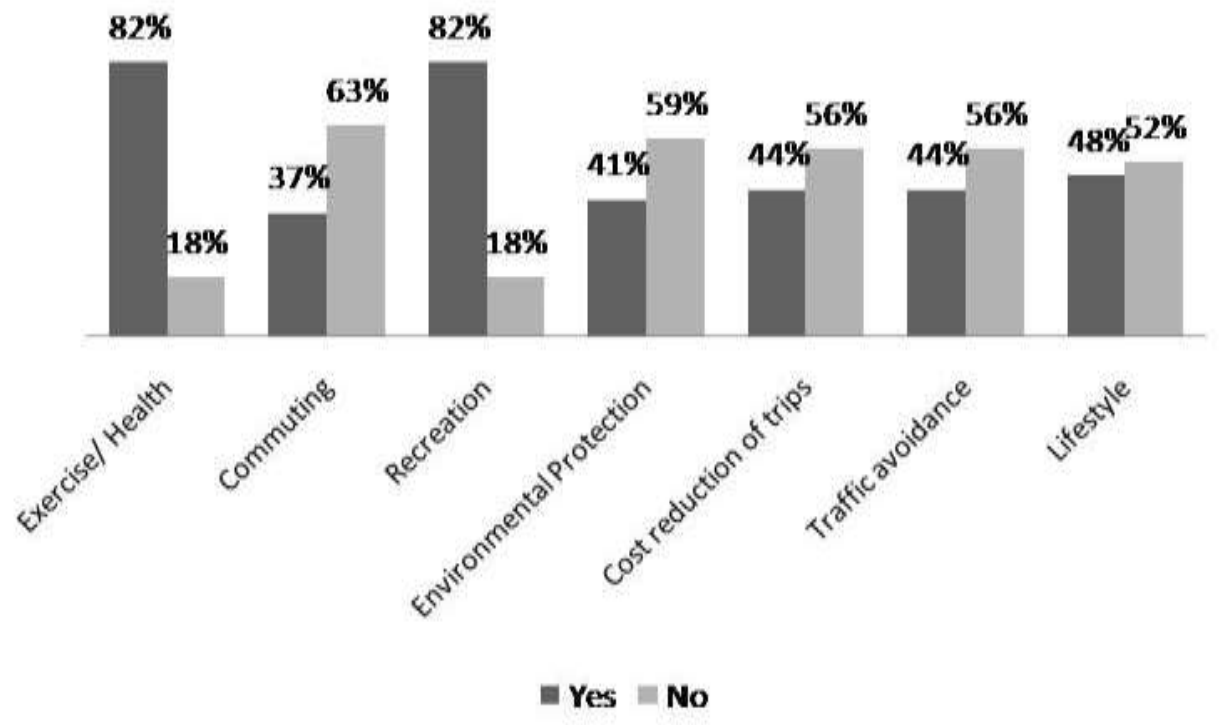

Figure 1. Bicycle use Trip Purposes

Regarding their level of accessibility to other means of transport, 93\% of interviewees revealed that there is a car available within their household while $28 \%$ mentioned that they are motorcycle owners.

Table 1 presents also the results regarding the factors that discouraged cyclists from using bicycle. Generally, respondents revealed a tendency for low ratings, since the "1" rating is the most common in all cases. However, motorcycle owners are discouraged more from cycling because of this extra alternative available for them. Moreover, long distances and the lack of appropriate bicycle infrastructure represent some factors that discourage cyclists to a greater extent. The general tendency of cyclists to give lower value answers can be explained by the frequent bicycle use. In the context of the present study, the majority of respondents stated daily bicycle use. This finding is also an indication that the sample is composed by cyclists who are not discouraged for cycling.

Apart from the mobility characteristics of cyclists, their interaction with pedestrians and motorized traffic was examined too. Participants were asked to report their last experiences (if any) of conflict with pedestrian and car (motor vehicle). Regarding the first case, $64 \%$ of respondents reported a conflict experience with pedestrian. The majority of reported cases took place along the shared path along the coastal zone (which was also the study area) and is related to noncompliant behaviour of pedestrians who violated the bicycle lane. However, this outcome may be affected by the selection of the study area, since it can have influenced the opinion of cyclists. Regarding perceived responsibility, it is worth highlighting that in $46 \%$ of the cases the cyclists gave the responsibility exclusively to pedestrians while they took all the responsibility themselves for $11 \%$ of the cases. Finally, as far as it concerns perceived priority, a percentage of $43 \%$ stated that pedestrians should be always given the priority while $48 \%$ stated that priority should depend on the place where the two users are met. Thus, according to the latter, priority should be generally given to pedestrians but not when they violate bicycle lanes. Finally, $8 \%$ of interviewees mentioned that priority should be always given to the cyclist. From the abovementioned results, it is 
easily observed a contrast between the perceived responsibility and priority. More specifically, the vast majority of cyclists tended to blame totally, or more, the pedestrian for the conflict event. However, their perception regarding priority is almost split between pedestrians and priority be given according to the type of infrastructure, while only few stated that cyclist should always have the priority. This outcome indicate that cyclists are aware that pedestrians are more vulnerable in a case of an incident with them, however they perceive them as responsible for the incident occurrence.

Regarding the case of a conflict with a car, the slight majority of respondents (54\%) reported an experience of such an event. A significant proportion, of them (20\%), concerns a perceived aggressive (or competitive) driving behaviour of drivers against cyclists. Also, $17 \%$ of participants reported a conflict event at a junction. The perceived aggressive behaviour by cars indicate that, contrary to the case of cyclistpedestrian interaction where pedestrians are considered as more vulnerable, cyclists have an initial tendency to adopt a negative perception towards motor vehicles. Similarly, to the previous case, cyclists were asked to give proportion of responsibility. In $52 \%$ of the cases, the respondents gave the responsibility exclusively to the driver while only $6 \%$ of them gave responsibility exclusively to themselves. Finally, regarding perceived priority, $40 \%$ of participants stated that cyclists should be always given priority while $54 \%$ of them believed that bicycle should be treated, when on road, according to the Greek Highway Code as a common vehicle. It is worth highlighting that the perception about the perceived priority of cyclists is different between the cases of pedestrians and cars. As observed by the results, in the cyclist-pedestrian case only $8 \%$ stated that cyclists should always have the priority while in the cyclist-car case, $40 \%$ of the participants stated the same about cyclists' priority. This finding is another indication that cyclists' perception is more negative towards cars compared to pedestrians. This can be possibly explained by the fact that cyclists are more vulnerable during their interaction with cars.

In conclusion, respondents expressed their preference regarding path types, when they coexist with pedestrians and motorized traffic. The results showed a clear tendency of cyclists to prefer to be separated from the other users. More specifically, the vast majority of them (98\%) preferred a separated bicycle lane, when they share paths with pedestrians. Additionally, concerning their coexistence with vehicular traffic, most cyclists (76\%) preferred a separate bicycle lane on the road than a bicycle lane on sidewalk.

\subsection{Inferential Statistics}

The present section describes the most important of the bivariate correlations occurred from the data analysis. Table 2 highlights these correlations along with the applied tests and the p-values results. Owing to the categorical nature of the variables (nominal and ordinal), non-parametric tests were chosen for the analysis. The selection of the appropriate test is related to the nature of the compared variables. Some general information regarding the application of the appropriate non-parametric tests are provided by [23]. One of the main disadvantages of the non-parametric tests is the difficulty in interpreting the results [24]. Thus, even if a significant correlation occurs, it is difficult to determine the level of correlation. Table 2 is segregated in 3 sections within an effort to separate the correlations which concern the exclusively the mobility characteristics of cyclists from those who involve their interaction with pedestrians and motor vehicles. 
Table 2. Inferential Tests Results

\begin{tabular}{|c|c|c|c|}
\hline \multicolumn{2}{|c|}{ Variables } & Test & p-value \\
\hline \multicolumn{4}{|c|}{ Mobility characteristics correlations } \\
\hline $\begin{array}{c}\text { gender } \\
\text { gender } \\
\text { frequency } \\
\text { frequency } \\
\text { frequency } \\
\text { frequency } \\
\text { duration } \\
\text { exercise } \\
\text { reach_dest } \\
\text { reach_dest } \\
\text { ped_confl_avert }\end{array}$ & $\begin{array}{c}\text { frequency } \\
\text { duration } \\
\text { duration } \\
\text { car_occup_avert } \\
\text { public_transp_avert } \\
\text { infr_lack_avert } \\
\text { long_dist_avert } \\
\text { long_dist_avert } \\
\text { car_avail } \\
\text { long_dist_avert } \\
\text { car_confl_avert }\end{array}$ & $\begin{array}{c}\text { Mann Whitney U } \\
\text { Mann Whitney U } \\
\text { Wilcoxon } \\
\text { Wilcoxon } \\
\text { Wilcoxon } \\
\text { Wilcoxon } \\
\text { Wilcoxon } \\
\text { Mann Whitney U } \\
\chi^{2} \\
\text { Mann Whitney U } \\
\text { Wilcoxon } \\
\end{array}$ & $\begin{array}{l}.047 \\
.001 \\
.000 \\
.000 \\
.000 \\
.000 \\
.000 \\
.044 \\
.008 \\
.000 \\
.000 \\
\end{array}$ \\
\hline \multicolumn{4}{|c|}{ correlations related to interaction with pedestrians } \\
\hline $\begin{array}{c}\text { ped_confl_avert } \\
\text { ped_confl } \\
\text { ped_confl } \\
\text { ped_respons } \\
\text { ped_respons } \\
\text { ped_respons } \\
\text { ped_priority } \\
\text { ped_priority } \\
\text { ped_priority } \\
\text { infr_ped } \\
\text { infr_ped } \\
\text { infr_ped } \\
\text { infr_ped }\end{array}$ & $\begin{array}{c}\text { duration } \\
\text { frequency } \\
\text { exercise } \\
\text { age } \\
\text { car_avail } \\
\text { ped_confl_type } \\
\text { gender } \\
\text { ped_confl_type } \\
\text { ped_respons } \\
\text { age } \\
\text { frequency } \\
\text { reach_dest } \\
\text { ped_confl_type }\end{array}$ & $\begin{array}{c}\text { Wilcoxon } \\
\text { Mann Whitney U } \\
\chi^{2} \\
\text { Wilcoxon } \\
\text { Mann Whitney U } \\
\text { Kruskall Wallis } \\
\chi^{2} \\
\chi^{2} \\
\text { Kruskall Wallis } \\
\text { Mann Whitney U } \\
\text { Mann Whitney U } \\
\chi^{2} \\
\chi^{2}\end{array}$ & $\begin{array}{l}.000 \\
.006 \\
.000 \\
.000 \\
.011 \\
.000 \\
.040 \\
.024 \\
.000 \\
.017 \\
.013 \\
.007 \\
.003\end{array}$ \\
\hline \multicolumn{4}{|c|}{ correlations related to interaction with vehicular traffic } \\
\hline $\begin{array}{c}\text { car_confl_avert } \\
\text { car_confl_avert } \\
\text { car_confl_avert } \\
\text { car_confl_avert } \\
\text { car_confl } \\
\text { car_confl } \\
\text { car_respons } \\
\text { car_respons } \\
\text { car_respons } \\
\text { car_respons } \\
\text { infr_traffic } \\
\text { infr_traffic } \\
\text { infr_traffic } \\
\text { infr_traffic }\end{array}$ & $\begin{array}{c}\text { gender } \\
\text { frequency } \\
\text { duration } \\
\text { infr_lack_avert } \\
\text { frequency } \\
\text { reach_dest } \\
\text { duration } \\
\text { exercise } \\
\text { reach_dest } \\
\text { car_confl_type } \\
\text { frequency } \\
\text { exercise } \\
\text { reach_dest } \\
\text { car_priority }\end{array}$ & $\begin{array}{c}\text { Mann Whitney U } \\
\text { Wilcoxon } \\
\text { Wilcoxon } \\
\text { Wilcoxon } \\
\text { Mann Whitney U } \\
\chi^{2} \\
\text { Wilcoxon } \\
\text { Mann Whitney U } \\
\text { Mann Whitney U } \\
\text { Kruskall Wallis } \\
\text { Mann Whitney U } \\
\chi^{2} \\
\chi^{2} \\
\chi^{2}\end{array}$ & $\begin{array}{l}.006 \\
.004 \\
.000 \\
.000 \\
.006 \\
.000 \\
.000 \\
.022 \\
.010 \\
.000 \\
.032 \\
.040 \\
.023 \\
.010\end{array}$ \\
\hline
\end{tabular}

Regarding the socio-demographic characteristics of cyclists, gender was found to affect both frequency and duration of cycling. More specifically, males were found to have a tendency for increased use of bicycle, compared to females. Focusing on the factors that discourage cyclists from cycling, car occupancy, use of public transportation, lack of cycling infrastructure and long distances were found to be more influential to participants that stated bicycle use 1-2 times/ month or seldom, compared to those who cycle every day or 4-5 times a week. Also, cyclists who bicycle for exercise are less discouraged by long distances. Car availability is, as expected related to using bicycle in order to go to destinations as work place or school. Moreover, these cyclists are also less influenced by long distances. This outcome may be related to the necessity of using bicycle, since no other options exist.

Regarding the interaction with pedestrians, a correlation is observed between the conflict experience with a pedestrian and the frequency of cycling $(\mathrm{p}<0.01)$ as well exercise as a purpose of cycling. The first correlation indicates that the high frequency 
of cycling also increases the possibility of conflict with pedestrian. Moreover, cyclists who use bicycle for exercising is also possible to use the bicycle lane along the coastal zone, due to its characteristics, and therefore it is possible to meet with pedestrians to a greater extent. The perceived responsibility of pedestrians is highly correlated with the type of conflict and cyclist's age $(p<0.001)$ as well the accessibility of cyclists to private car $(\mathrm{p}<0.05)$. The young and middle aged cyclists tend to accuse mostly the pedestrians while more aged pedestrians blamed exclusively themselves to a greater extent. Perceived responsibility is also highly correlated with the reported conflict type ( $p<0.001)$. Table 3 highlights the mean value of perceived responsibility per type of conflict. It is assumed that a value of 1 means that the cyclist perceives himself/herself as totally responsible while a value of 5 indicates that pedestrians or motor vehicle drivers are considered as fully responsible for the conflict. Cyclists who reported a conflict on the shared path, gave the responsibility exclusively to pedestrians to a greater extent, compared to the rest cases. This outcome may indicate the dissatisfaction of cyclists, when they encounter other users in a space designed only for them. On the other hand, cyclists admit their responsibility for conflict events that took place on sidewalks (infrastructure designed for pedestrians). Moreover, cyclists who also have access to car were stricter with pedestrians, since they may interact with them as drivers too and be negatively prejudiced. Concerning perceived priority, during the interaction with pedestrians, correlations are observed with gender $(\mathrm{p}<0.05)$, the reported type of conflict $(\mathrm{p}<0.05)$ and perceived responsibility $(\mathrm{p}<0.001)$. According to the results, the majority of female participants stated that priority should be given to pedestrians while most of men stated that priority should depend on the place where the meeting occurs.

Likewise, the conflict with a pedestrian, the frequency of cycling is also related with a conflict with a motor vehicle $(p<0.01)$. In terms of socio-demographic characteristics, it is found that a potential conflict with a car discourages male cyclists to a lesser extent, compared to females. Also, frequency and duration of cycling are related to the level of discourage by a potential conflict with a motor vehicle. In particular, more discouraged cyclists also tend to cycle less frequently and for less time. Finally, a positive correlation is found between discourage by a potential conflict with a car and discourage by the lack of appropriate infrastructure. This finding may indicate that an upgrade of cycling infrastructure or the development of a better connected cycling network, would also have an impact on an increase in bicycle use. Moreover, the conflict experience with a motor vehicle is highly correlated with cyclists who stated that use bicycle for commuting purposes also $(\mathrm{p}<0.001)$. Also, a correlation occurred between perceived responsibility of the driver and the type of conflict event $(\mathrm{p}<0.001)$. With reference to the results of Table 3 , cyclists tend to always accuse drivers of motor vehicles apart from the cases that they did an illegal movement. The perceived responsibility is correlated with the duration of cycling $(\mathrm{p}<0.001)$ as well as with exercise and commuting as trip purposes $(\mathrm{p}<0.05)$ too. More particularly, cyclists who stated that cycle for more time also perceive car drivers as more responsible. Also cyclists who also commute accused primarily the car drivers to a lesser extent, probably owing to their higher interaction with vehicular traffic.

Moreover, some correlations derived between the preferred infrastructure type, when interacting with motorized traffic, and frequency of cycling $(\mathrm{p}<0.05)$, exercise, commuting $(\mathrm{p}<0.05)$ and perceived priority when cyclists are met with the motorized traffic $(\mathrm{p}<0.05)$. More specifically, the most frequent users of bicycle prefer a bicycle lane adjacent to the vehicular traffic while the less frequent prefer bicycle lanes on sidewalks. Finally, cyclists who mentioned that bicycle should be treated, by the Highway Code, as a common vehicle prefer bicycle lane across the road while those who stated that cyclists should be always given the priority prefer bicycle lanes on sidewalks. 
Table 3. Mean Values of Perceived Responsibility per Conflict Type

\begin{tabular}{|c|c|c|c|c|c|}
\hline \multicolumn{6}{|c|}{ Conflicts with pedestrians and mean values } \\
\hline $\begin{array}{c}\text { Conflict at the } \\
\text { shared-use path } \\
\text { of the coastal } \\
\text { zone }\end{array}$ & $\begin{array}{c}\text { Conflict at the shared- } \\
\text { use path of the coastal } \\
\text { zone(narrow segment) }\end{array}$ & $\begin{array}{c}\text { Conflict on } \\
\text { a sidewalk }\end{array}$ & $\begin{array}{c}\text { Conflict on a } \\
\text { sidewalk } \\
\text { (with a } \\
\text { bicycle lane) }\end{array}$ & $\begin{array}{c}\text { Conflict with } \\
\text { a pedestrian } \\
\text { crossing the } \\
\text { road (no } \\
\text { crosswalk) }\end{array}$ & $\begin{array}{c}\text { Conflict with a } \\
\text { pedestrian } \\
\text { crossing the } \\
\text { road } \\
\text { (crosswalk) }\end{array}$ \\
\hline 4.42 & 4.16 & 2.00 & 3.38 & 3.48 & 3.09 \\
\hline \multicolumn{7}{|c|}{ Conflicts with motor vehicles and mean values } \\
$\begin{array}{c}\text { Aggressive } \\
\text { driving } \\
\text { behaviour on a } \\
\text { road segment }\end{array}$ & $\begin{array}{c}\text { Illegal car movement on } \\
\text { a road segment }\end{array}$ & $\begin{array}{c}\text { Conflict at } \\
\text { an } \\
\text { intersection }\end{array}$ & $\begin{array}{c}\text { Illegal } \\
\text { bicycle } \\
\text { movement on } \\
\text { a road } \\
\text { segment }\end{array}$ & $\begin{array}{c}\text { Car is turning } \\
\text { at an } \\
\text { intersection } \\
\text { and blocks } \\
\text { bicycle's } \\
\text { course }\end{array}$ & $\begin{array}{c}\text { Parked car } \\
\text { passenger } \\
\text { opens the door } \\
\text { whyclists } \\
\text { passes }\end{array}$ \\
\hline 4.13 & 4.58 & 4.25 & 2.40 & 4.53 & 4.69 \\
\hline
\end{tabular}

\section{Conclusions}

The purpose of the present paper was the investigation of the preferences and mobility characteristics of cyclists together with their perceived interaction with pedestrians and motorized vehicles. Regarding the collected sample, cyclists are mostly men, young and middle aged. Moreover, they use bicycle primarily for exercise and recreation and less for commuting purposes. A general outcome derived from the analysis is that cyclists prefer to interact with other users the less possible; participants revealed a tendency for preferring bicycle lanes that separate them from pedestrians and motorized traffic. However, despite the aforementioned outcome, the interaction with the other users does not discourage them from cycling, especially when they interact with pedestrians.

The analysis which focused on the conflict events of cyclists, revealed some differences concerning the perception of participants regarding pedestrians and motor vehicles. Generally, a tendency of cyclists to accuse mostly the other users was observed. However, the perceived responsibility of pedestrians is influenced by the type of the reported conflicts. On the other hand cyclists accuse mostly the drivers, regardless the conflict type. Finally, it should be highlighted and commented that the variable which refers to the last conflict type of cyclists is not able to be evaluated regarding its validity. Generally, cyclists focused on cases where the other user was responsible for the conflict occurrence (e.g., "the pedestrian violated the bicycle lane"). However, considering the aforementioned example, during the questionnaire survey, was observed in many cases dangerous and noncompliant behaviour of cyclists e.g. they were moving very fast, outside the bicycle lane. The absence of these types of reported behaviour may indicate that cyclists form their opinion, about the rest users, focused on the inappropriate behaviour of the others and not on theirs.

All in all, the use of bicycle is crucial in modern societies, in terms of personal and public health and sustainability. Policy makers should move their planning towards the increase of use of more sustainable modes of transport. In order to accomplish this, and shift people from vehicular to soft modes, they should understand people's perceptions and attitudes. This paper attempted to investigate cyclists' perception regarding the presence other users, their motivations and infrastructure preferences. Some findings related to the aforementioned issues are found but, more research related to these issues should be done, in order to overcome some of the limitations of this study. First of all, the study took place in a specific area oh the city of Thessaloniki therefore, the results may be considered as localized and biased, as only specific types of interactions occurred. A simple example refers to the high proportion of conflict events with pedestrians, along the infrastructure of the coastal zone. Moreover, the reported conflicts, in the majority of cases, refer to events where the other user was responsible. However, during the surveys, many cyclists were 
noticed moving in areas for pedestrians, but none of the participants reported any similar event. Some potential suggestions for further research would include the conduction of a new survey which will combine stated preference and revealed preference data, aiming in the development of behavioral models. Moreover, similar surveys can be conducted in different areas and cities, in order to combine different types of interactions and attitudes. Finally, studies of similar approach can be conducted, addressing to pedestrians or motor vehicle drivers, within an effort to observe their perception about cyclists. In conclusion, apart from the aforementioned limitations, the outcomes of the present study can be considered as a first step towards a better understanding of cyclist's attitudes and perceptions towards the other users of the road.

\section{Acknowledgments}

This paper is a revised version of a paper entitled "The interrelation between bicyclists, pedestrians and vehicular traffic: investigation of bicycle users' perception and needs in relation to the other users of the road" presented in Greek at $6^{\text {th }}$ Panhellenic Conference in Road Safety, Athens, 12-13 March 2015.

\section{References}

[1] G. Deenihan and B. Caulfield, "Estimating the health economic benefits of cycling", Journal of Transport \& Health, doi:10.1016/j.jth.2014.02.001, vol. 1, no. 2, (2014), pp. 141-149.

[2] M. Börjesson and J. Eliasson, "The value of time and external benefits in bicycle appraisal", Transportation Research Part A: Policy and Practice, doi:10.1016/j.tra.2012.01.006, vol. 46, no. 4, (2012), pp. 673-683.

[3] D. Rojas-Rueda, A. de Nazelle, M. Tainio and M. J. Nieuwenhuijsen, "The health risks and benefits of cycling in urban environments compared with car use: health impact assessment study", BMJ (Clinical Research Ed.), 343, d4521. doi:10.1136/bmj.d4521, (2011).

[4] P. L. Owens, "Conflict as a social interaction process in environment and behaviour research: the example of leisure and recreation research", Journal of Environmental psychology, vol. 5, no. 3, (1985), pp. 243259.

[5] R. L. Moore, "Conflicts on Multiple Trails: Synthesis of the Literature and State of the Practice", Report FHWA-PD-94-031, Federal Highway Administration, Washington, DC, USA, (1994).

[6] L. Kang, Y. Xiong and F. L. Mannering, "Statistical analysis of pedestrian perceptions of sidewalk level of service in the presence of bicycles", Transportation Research Part A: Policy and Practice, doi:10.1016/j.tra.2013.05.002, vol. 53, (2013), pp. 10-21.

[7] M. Kiyota and U. Vandebona, "Bicycle and Pedestrian Traffic Conflicts on Shared Pavements", retrieved from www.velomondial.net/velomondiall2000/PDF/KIYOTA.PDF at 25/6/2014, (2000).

[8] D. Uzell, J. Groeger, R. Leach, A. Wrigh, N. Ravenscroft and G. Parker, "User Interaction on NonMotorised Shared Use Routes: Final Report", University of Surrey for The Countryside Agency, Guildford, Surrey, England, (2000).

[9] A. Singh, "A study of cyclist behaviour and perceptions on shared space", Proceedings of the 1st Civil and Environmental Engineering Student Conference, London, UK, (2012) June 25-26.

[10] Atkins (Department for Transport). Shared Use Operational Review 2012, retrieved from https://www.gov.uk/government/uploads/system/uploads/attachment_data/file/9181/atkins-shared-useoperational-review.pdf at 03/03/2015, (2012).

[11] L. Ružič, "Cycle climate and conflict between pedestrians and cyclists in Ljubljana pedestrian zone, retrieved from http://www.champ-cycling.eu/en/upload/WP3_docs/CYCLE\%20CLIMATE\%20AND\% 20CONFLICT\%20BETWEEN\%20PEDESTRIANS\%20AND\%20CYCLISTS\%20IN\%20LJUBLJANA \%20PEDESTRIAN\%20ZONE.pdf at 03/03/2015, (2013).

[12] M. Winters, S. Babul, H. J. E. H. J. Becker, J. R. Brubacher, M. Chipman, P. Cripton, M. D. Cusimano, S. M. Friedman, A. M. Harris, G. Hunte, M. Monro, C. C. O. Reynolds, H. Shen and K. Teschke, "Safe Cycling: How Do Risk Perceptions Compare With Observed Risk?", Canadian Journal of Public Health, vol. 103, no. 3, (2012), pp. 542-547.

[13] E. S. Chataway, S. Kaplan, T. A. S. Nielsen and C. G. Prato, "Safety perceptions and reported behavior related to cycling in mixed traffic: A comparison between Brisbane and Copenhagen", Transportation Research Part F: Traffic Psychology and Behaviour, doi:10.1016/j.trf.2013.12.021, vol. 23, (2014), pp. 32-43.

[14] A. R. Lawson, V. Pakrashi, B. Ghosh and W. Y. Szeto, "Analysis of the perception of safety among cyclists", Association for European Transport and Contributors, (2012), pp. 1-11. 
[15] J. P. O'Connor and T. D. Brown, "Riding with the sharks: serious leisure cyclist's perceptions of sharing the road with motorists", Journal of Science and Medicine in Sport / Sports Medicine Australia, doi:10.1016/j.jsams.2008.11.003, vol. 13, no. 1, pp. 53-8.

[16] J. Shunping, P. Hongqin, G. Jinyi and C. Haibo, "Quantitative analysis of impact of bicycles on vehicles in urban mixed traffic", Journal of Transportation Systems Engineering and Information Technology, vol. 8, no. 2, (2008), pp. 58-63.

[17] S. Reid, "The roots of driver behaviour towards cyclists", Publication of: Association for European Transport, (2002)

[18] M. Johnson, J. Oxley, S. Newstead and J. Charlton, "Safety in numbers? Investigating Australian driver behaviour, knowledge and attitudes towards cyclists", Accident Analysis \& Prevention, vol. 70, (2014), pp. $148-154$

[19] E. Paschalidis, "Investigation of the interaction between bicyclists and pedestrians", Master Thesis. Supervisor: Basbas S., Inter-departmental Postgraduate Programme, "Planning, Organization and Management of Transport Systems", Aristotle University of Thessaloniki, Department of Civil Engineering and Department of Rural and Surveying Engineering, Hellenic Institute of Transport, (2013).

[20] M. Prodromou, "Investigation of the interaction between bicyclists and drivers", Master Thesis. Supervisor: Basbas S., Inter-departmental Postgraduate Programme, "Planning, Organization and Management of Transport Systems", Aristotle University of Thessaloniki, Department of Civil Engineering and Department of Rural and Surveying Engineering, Hellenic Institute of Transport, (2013).

[21] S. Basbas, V. Tetou and I. Politis, "Ordinal and binary logistic logit models for examination of behavioral, infrastructure and perception factors influencing biking", WIT Transactions on the Built Environment, (130), (2013).

[22] P. Kostoula, A. Spiliopoulou and C. Stamatiou. "Evaluation of the new bicycle road at Thessaloniki", Diploma Thesis, Technological Institute of Serres, Department of Geoinformatics and Surveying (2010)

[23] M. Gill and L. Jonker, "An introduction to inferential statistics: A review and practical guide", Radiography, vol. 17, no. 1, (2011).

[24] H. Tanya, "Parametric and nonparametric: Demystifying the terms", Mayo Clinic, (2014).

\section{Authors}

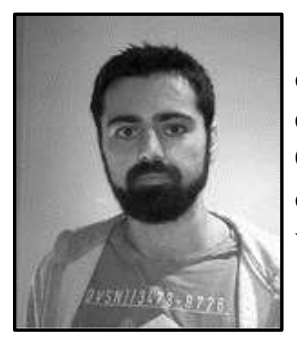

Evangelos Paschalidis, is an MSc transport engineer (Aristotle University of Thessaloniki, Greece). He also holds a Diploma in Rural and Surveying engineering from the same institution. Currently he is a $\mathrm{PhD}$ student in the Choice Modelling Centre (Institute for Transport Studies) of the University of Leeds. Research Interests: advanced choice modelling, econometrics, vulnerable road users, behavioral and attitudinal analysis.

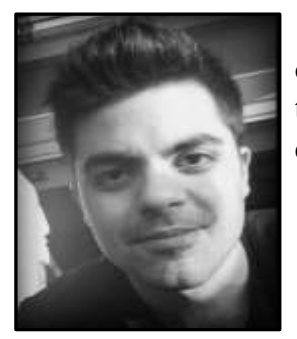

Michail Prodromou, is an MSc transport engineer (Aristotle University of Thessaloniki, Greece). He also holds a Diploma as a Civil Engineer from the same institution. Research Interests: Interaction between cyclists and drivers and the introduction of bicycle as an alternative mean of transport.

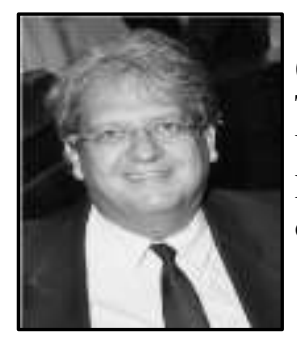

Socrates Basbas, holds a Diploma in Rural \& Surveying Engineering (1985) from the Aristotle University of Thessaloniki (AUTh), M.Sc. in Transportation Planning and Engineering (1986) from the University of Leeds, U.K., and Ph.D. (1997) in Transportation from AUTh. He is currently a Professor at AUTh, Faculty of Rural and Surveying Engineering, Department of Transportation and Hydraulic Engineering. 


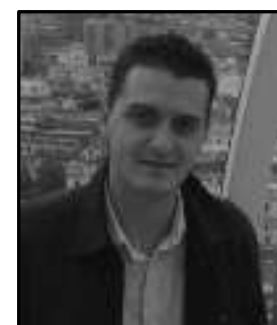

Ioannis Politis, holds a Phd Degree in Transportation Planning and Engineering. He is Lecturer at the Civil Engineering Department of Aristotle University of Thessaloniki, Greece. He is the author, or co-author of more than 80 research papers which have been published in international and national journals, books and conferences, focusing on transportation engineering, mobility management, sustainable modes of transport etc. He has been involved in various research and EU funded projects. 